\title{
Pharmacokinetic disposition in sheep of various vitamin E preparations given orally or intravenously
}

\author{
BY M. HIDIROGLOU \\ Animal Research Centre, Agriculture Canada, Ottawa KIA OC6, Canada \\ AND K. KARPINSK I \\ Food Directorate, Health and Welfare Canada, Tower B, Place Vanier, Vanier, \\ Ontario K1A $1 B 8$, Canada
}

(Received 4 September 1987 - Accepted 19 January 1988)

1. Increases in plasma tocopherol concentrations were compared in sheep after a single oral administration of (per kg body-weight): $67 \mathrm{mg} \mathrm{D-}$ and $91 \mathrm{mg} \mathrm{DL-epimers} \mathrm{of} \alpha$-tocopherol, and $74 \mathrm{mg} \mathrm{D}$ - and $100 \mathrm{mg}$ DL-epimers of $\alpha$-tocopheryl acetate, or intravenous administration of DL- $\alpha$-tocopherol and DL-epimers of DL- $\alpha$-tocopheryl acetate.

2. The results showed that biological availability was higher after $D$ - $\alpha$-tocopherol dosing than after the other forms. Intravenous administration of $D-\alpha$-tocopherol acetate was a more effective way of dosing in sheep than equivalent intravenous amounts of $\mathrm{DL}-\alpha$-tocopheryl acetate or DL- $\alpha$-tocopherol.

At present very little is known about the absorption and pharmacokinetic disposition of various forms of tocopherol administration to sheep. In previous studies (Hidiroglou, 1986; Hidiroglou \& Karpinski, 1987) we examined the biological availability of $\alpha$ tocopherol following its administration to sheep by various routes. In the present report we describe the pharmacokinetic disposition of three tocopherol formulations (two esters, $\mathrm{D}-\alpha$ - and DL- $\alpha$-tocopheryl acetate and one free form, DL- $\alpha$-tocopherol) given intravenously or four (including $\mathrm{D}-\alpha$-tocopherol) given orally, to sheep.

\section{EXPERIMENTAL \\ Animals}

Yearling crossbred wethers, weighing $50-57 \mathrm{~kg}$, were used. All animals originated from a flock born and raised in confinement. The animals were fed, for 6 months before and during the experiment, on a diet which consisted of $(\mathrm{g} / \mathrm{kg})$ grass silage 400 , hay 400 , maize silage 200.

The sheep were placed in metabolism cages $10 \mathrm{~d}$ before dosing. During this period blood samples were obtained daily ( 08.00 hours) from the jugular veins by venepuncture to obtain baseline values.

Expt 1. Four crossbred wethers $(50-57 \mathrm{~kg})$ were used. A system of rotation in administering the four forms of vitamin $E$ to the four sheep was employed in order to minimize variations between concentration time curves. Each sheep was sequentially treated orally with a single dose of vitamin $\mathrm{E}$ in the following order $(\mathrm{mg} / \mathrm{kg}$ body-weight $)$ : treatment 1, D- $\alpha$-tocopheryl acetate (74); treatment 2 , DL- $\alpha$-tocopherol (91); treatment 3, DL- $\alpha$-tocopheryl acetate (100); treatment 4, D- $\alpha$-tocopherol (67).

The various vitamin $\mathrm{E}$ compounds were administered in gelatin capsules. The interval period between doses was 1 month. Each dose was administered early in the morning $(08.00$ hours). Blood samples of $5 \mathrm{ml}$ were collected from the jugular vein before dosing and then at regular time intervals from $1 \mathrm{~h}$ to $320 \mathrm{~h}$ following dosing. The heparinized blood was 
centrifuged immediately and the plasma stored at $-20^{\circ}$ until analysed for $\alpha$-tocopherol. Analyses were performed within 2 weeks following sampling.

Expt 2. Fourteen crossbred wethers $(50-60 \mathrm{~kg})$ were used. They were divided at random into three groups for intravenous dosing $(\mathrm{mg} / \mathrm{kg}$ body-weight): treatment 5 , five sheep given DL- $\alpha$-tocopheryl acetate (20); treatment 6 , five sheep given $D$ - $\alpha$-tocopheryl acetate (14.8); treatment 7 , four sheep given DL- $\alpha$-tocopherol (18.2).

The intravenous preparations were prepared in our laboratory as follows. An amount of DL- $\alpha$-tocopherol, or the ester forms, equivalent to the injected dose was stirred with $1 \mathrm{~g}$ Tween 80 . To this was added $30 \mathrm{ml}$ diethyl ether and the mixture shaken for $20 \mathrm{~min}$. The diethyl ether layer was evaporated under nitrogen and then $10-15 \mathrm{ml}$ water added. This solution was used for slow intravenous injection. Blood samples were collected before dosing and then at regular time intervals from 1 min to $319 \mathrm{~h}$ following dosing.

\section{Analytical methods}

Quantification of vitamin E in the plasma of sheep was performed by high-performance liquid chromatography using a fluorescent detector (McMurray \& Blanchflower, 1979).

\section{Statistical methods}

Absorption of the various tocopherol forms consisted of a lag phase and, in many cases, a somewhat irregular absorption phase. As a result, standard absorption models could not be consistently fitted to the values. Comparisons of the uptake phases were therefore based on repeated measures analyses of variance (Winer, 1971) applied to the models.

For the oral administration:

$$
\log \left(C_{i+1} / C_{i}\right)=\text { group }+ \text { sheep }+(\text { group } \times \text { sheep })+\text { time }+(\text { group } \times \text { time }) .
$$

For the intravenous administration:

$$
\log \left(C_{i+1} / C_{i}\right)=\text { group }+ \text { sheep within group }+ \text { time }+(\text { group } \times \text { time }) .
$$

The $\log \left(C_{i+1} / C_{i}\right)$ are logarithms of ratios of successive concentration measurements, and model parameters represent the standard main effects and interactions for groups, sheep and sampling times. Univariate analyses of $\log \left(C_{i+1} / C_{i}\right)$ and $\log \left(C_{i}\right)$ were also conducted at each time-point. Initial concentrations were considered as covariates in order to adjust for possible baseline differences in tocopherol levels. Treatment 7 (DL- $\alpha$-tocopherol administered by the intravenous route) was not included in the previously described analyses since absorption of this tocopherol form was regarded as instantaneous.

Elimination phases of the profiles were represented as sums of exponentials, $\Sigma A_{j} \mathrm{e}^{-K_{j} \times \text { time }}$. Estimation was based on non-linear least squares (SAS Institute, 1982). For the intravenous administration additional analyses were carried out using the univariate and repeated measures approaches which were described previously.

Univariate analyses of variance $F$ tests and pairwise $t$ tests were applied to a variety of statistics derived from the data, namely initial concentration $\left(C_{0}\right)$; terminal observed concentration $\left(C_{\mathrm{T}}\right)$; peak observed concentration $\left(C_{\max }\right)$; time to peak concentration $\left(t_{\max }\right)$; area under the concentration profile (AUC, calculated by the trapezoidal rule); and the exponential elimination rate constant ( $K$, derived from the non-linear least squares). Analyses of $C_{0}, C_{\mathrm{T}}, C_{\max }$ and $\mathrm{AUC}$ were carried out on the $\log$ scale. For $C_{\mathrm{T}}, C_{\max }$ and AUC, analyses incorporated initial concentration as a covariate. Pairwise comparisons were based on $t$ tests with standard errors derived from pooled analysis of variance mean squares. Averages on the log scale were transformed back to the original scale where they represent geometric means. Standard deviations on the log scale were multiplied by 100 to yield approximate coefficients of variation on the original scale. 


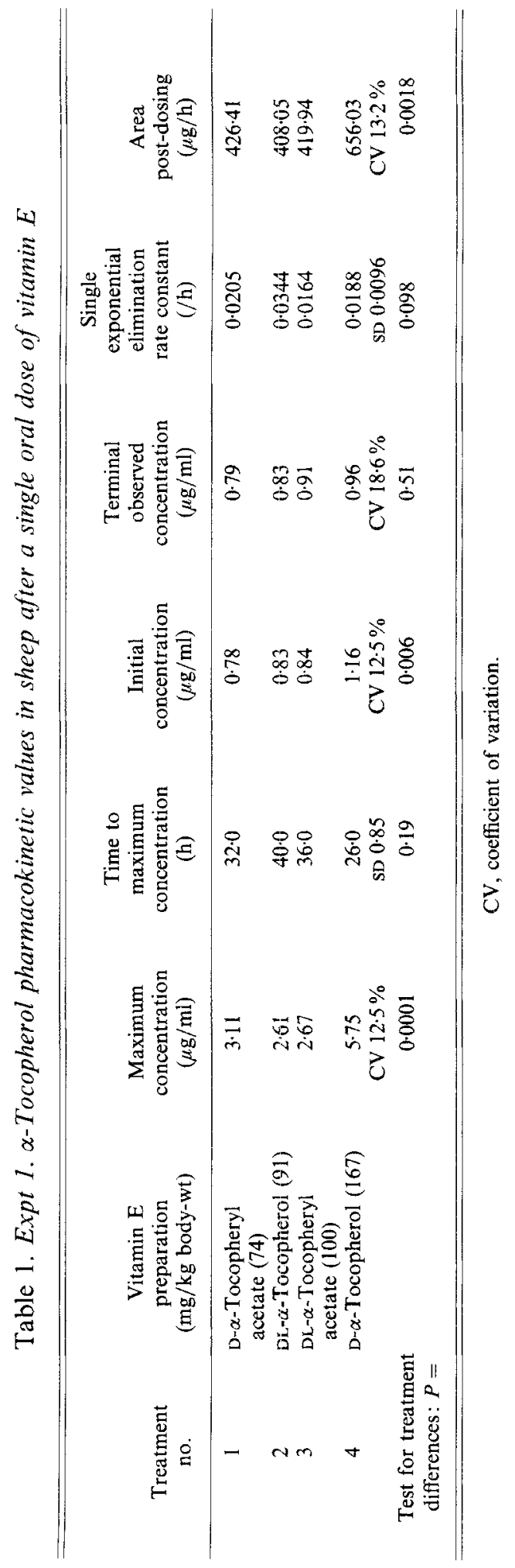



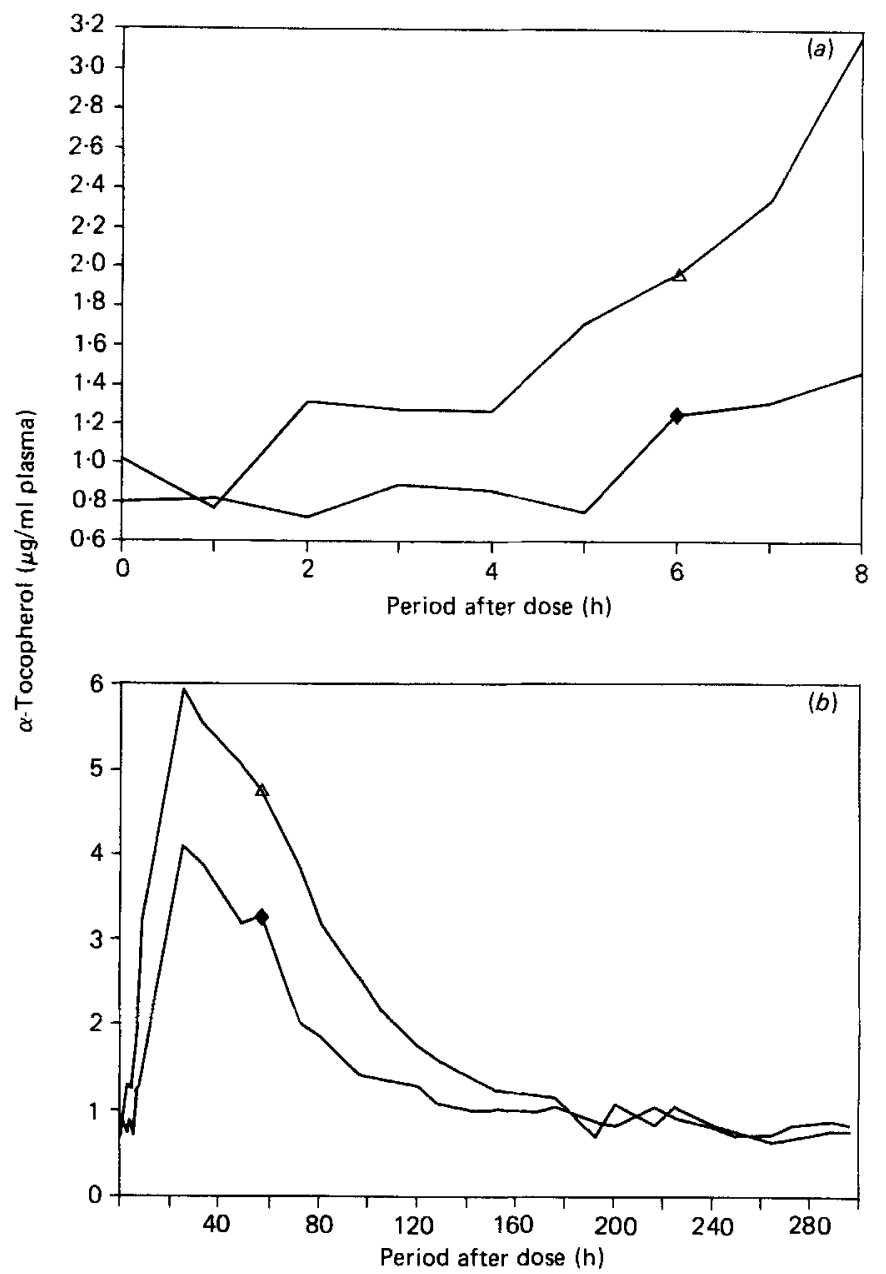

Fig. 1. Blood plasma $\alpha$-tocopherol concentrations in sheep no. 2 dosed with $\mathrm{D}$ - $\alpha$-tocopherol $(\triangle)$ or D$\alpha$-tocopheryl acetate $(\checkmark)$ orally (for details of treatments, see pp. $509-510$ ). (a) From 0 to $8 \mathrm{~h}$, and then (b) up to $280 \mathrm{~h}$.

\section{RESULTS}

\section{Oral administrations}

The first $24 \mathrm{~h}$ following oral tocopherol administration consisted of a lag period ranging from 4 to $7 \mathrm{~h}$ followed by a rapid absorption phase. The rates of increase in tocopherol levels for the four treatments were significantly different over this period $(P=0.047$ for treatment differences in the repeated measures analysis). This result was primarily due to treatment 4 ( $D-\alpha$-tocopherol) which had a slightly shorter lag time and faster absorption after the lag period. Peak concentrations were observed between 24 and $48 \mathrm{~h}$ following administration. The difference in absorption characteristics between treatment 4 (D- $\alpha-$ tocopherol) and the other three treatments is reflected in an increased $C_{\max }$ and AUC for treatment 4 (Table 1). Differences in the average $t_{\max }$ were not statistically significant (Table 1).

The elimination portions of the profiles $(72-320 \mathrm{~h})$ were adequately represented by a single exponential elimination curve, $A \mathrm{e}^{-K \times \text { time }}$. Average elimination rate constants, $K$, are 


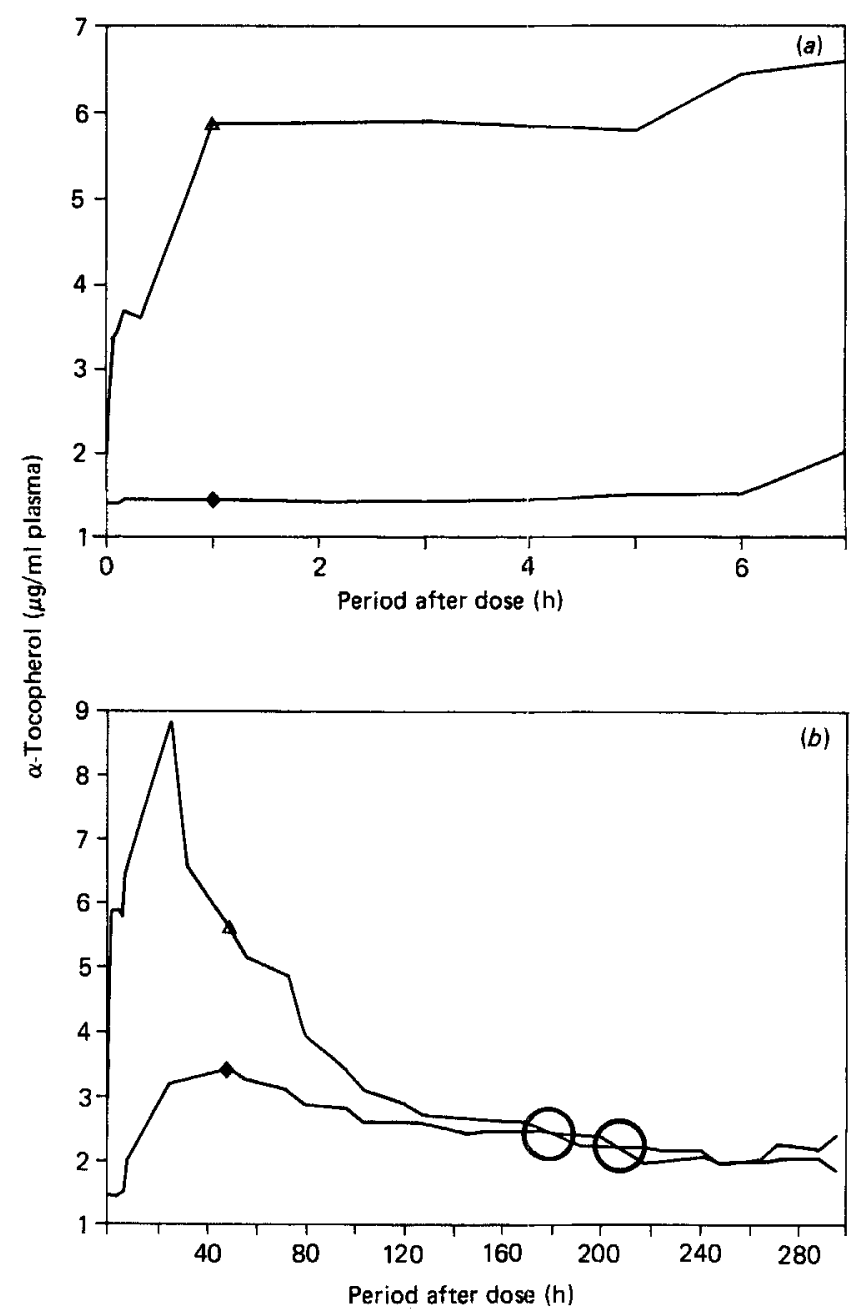

Fig. 2. Blood plasma $\alpha$-tocopherol concentration in sheep no. 1 dosed with $D$ - $\alpha$-tocopheryl acetate $(\triangle)$ or DL- $\alpha$-tocopheryl acetate $(\triangleleft)$ intravenously (for details of treatments, see pp. 509-510). (a) From 0 to $8 \mathrm{~h}$, and then $(b)$ up to $280 \mathrm{~h}$.

presented in Table 1. There is a suggestion $(P=0.098)$ that treatment 2 (DL- $\alpha$-tocopherol) tended to have a faster elimination rate than the other treatments.

Profiles of one sheep from treatment 1 (D- $\alpha$-tocopheryl acetate) and treatment 4 (D- $\alpha$ tocopherol) are provided in Fig. 1. Profiles for treatment 2 (DL- $\alpha$-tocopherol) and treatment 3 (DL- $\alpha$-tocopheryl acetate) generally resembled the treatment- 1 profile.

The four tocopherol forms were administered in the same sequence for all four sheep so there was a possibility of carry-over or sequence effect. The elimination interval between successive administrations appeared to be adequate. Terminal concentrations (at $320 \mathrm{~h}$ ) were comparable for all treatments (Table 1). Nevertheless, treatment 4 (D- $\alpha$-tocopherol) produced significantly elevated initial concentrations (Table 1). To investigate the extent to which $C_{\max }$ and AUC differences were associated with $C_{0}$ differences, an analysis of covariance was carried out. Adjusted $C_{\max }$ for treatment 4 (D- $\alpha$-tocopherol) remained significantly higher $(P<0.02)$. Treatment $4(\mathrm{D}-\alpha$-tocopherol $)$ also had the highest 


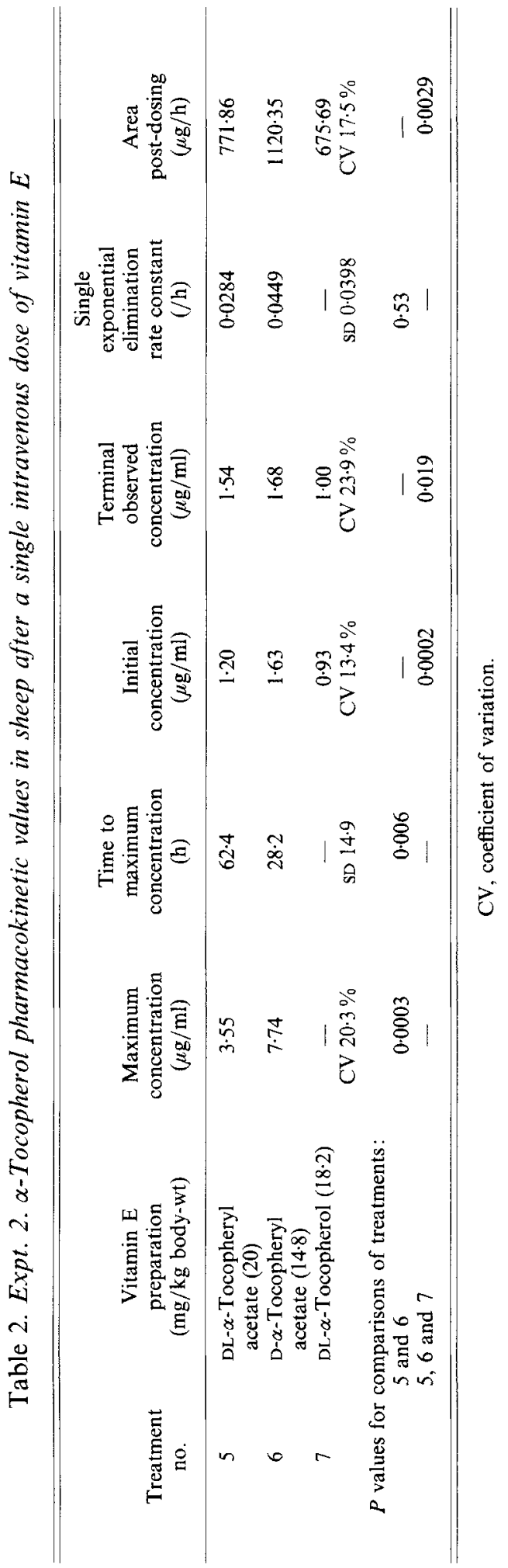




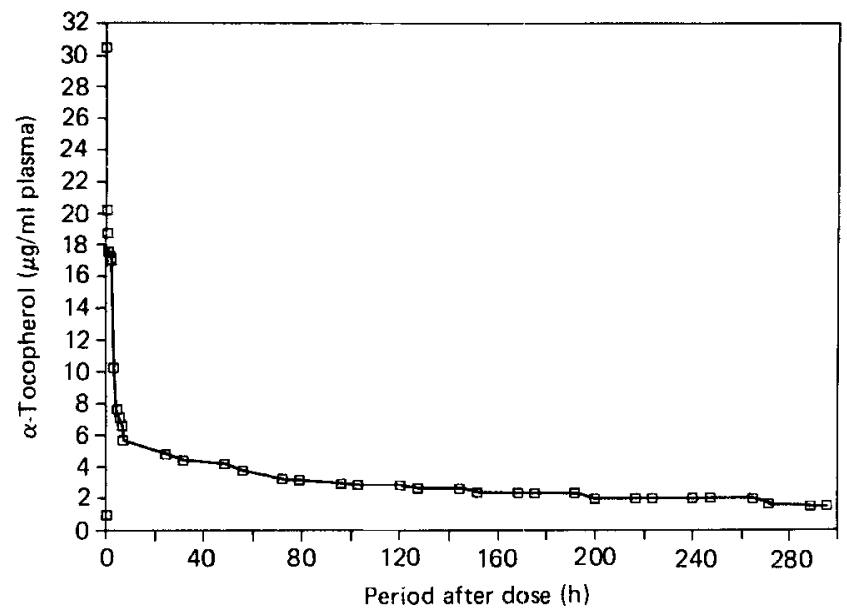

Fig. 3. Blood plasma $\alpha$-tocopherol concentration in sheep dosed intravenously with DL- $\alpha$-tocopherol (for details of treatments, see pp. 509-510).

Table 3. Exponential equation parameter estimates for DL- $\alpha$-tocopherol (treatment $7^{*}$ ) (Model: base $+A \mathrm{e}^{-\alpha t}+B \mathrm{e}^{-\beta t}+C \mathrm{e}^{-\gamma t}$. Values are means with their standard errors)

\begin{tabular}{clccccccc}
\hline $\begin{array}{c}\text { Sheep } \\
\text { no. }\end{array}$ & $\begin{array}{c}\text { Base } \\
(\mu \mathrm{g} / \mathrm{ml})\end{array}$ & $\begin{array}{c}A \\
(\mu / \mathrm{ml})\end{array}$ & $\begin{array}{c}\alpha \\
(/ \mathrm{h})\end{array}$ & $\begin{array}{c}B \\
(\mu \mathrm{g} / \mathrm{ml})\end{array}$ & $\begin{array}{c}\beta \\
(/ \mathrm{h})\end{array}$ & $\begin{array}{c}C \\
(\mu \mathrm{g} / \mathrm{ml})\end{array}$ & $\begin{array}{c}\gamma \\
(/ \mathrm{h})\end{array}$ \\
\hline \multirow{2}{*}{1} & Mean & 0.971 & 38.874 & 32.6485 & 27.372 & 0.6862 & 4.062 & 0.0110 \\
& SE & 1.295 & $5 \cdot 750$ & 8.2882 & 1.7014 & 0.1229 & 1.287 & 0.0094 \\
2 & Mean & 0.657 & 79.314 & 22.3804 & 10.341 & 0.7570 & 3.018 & 0.0069 \\
& SE & 1.685 & $2 \cdot 046$ & 1.2849 & 1.100 & 0.2021 & 1.462 & 0.0081 \\
3 & Mean & 0.898 & 55.043 & 96.4416 & 15.4814 & 0.2899 & 3.555 & 0.0052 \\
& SE & 3.581 & 74.359 & 80.8119 & 1.0948 & 0.0453 & 2.926 & 0.0101 \\
4 & Mean & 1.107 & 11.455 & 49.9636 & 12.0296 & 0.7623 & 0.640 & 0.0012 \\
& SE & 32.745 & 2.786 & 14.8386 & 0.3409 & 0.0643 & 32.606 & 0.0663 \\
\hline \hline
\end{tabular}

* For details, see p. 510.

adjusted AUC but the difference between treatment 4 and the other three treatments was markedly reduced.

\section{Intravenous administrations}

Tocopherol absorption for treatment 7 (DL- $\alpha$-tocopherol) was regarded as instantaneous. For treatments 5 (DL- $\alpha$-tocopheryl acetate) and 6 (D- $\alpha$-tocopheryl acetate) absorption was generally irregular. In some cases there was an apparent lag lasting up to $6 \mathrm{~h}$ before any increase in tocopherol levels was noted. Other sheep had an initial period of rapid increase followed by a plateau and another period of rapid increase. For example, one of the sheep in treatment 6 (D- $\alpha$-tocopheryl acetate) had an initial tocopherol level of $1.23 \mu \mathrm{g} / \mathrm{ml}$; by $1 \mathrm{~h}$ this level had increased to $5.88 \mu \mathrm{g} / \mathrm{ml}$; the level remained essentially constant for the next $4 \mathrm{~h}$ with a level at $5.79 \mu \mathrm{g} / \mathrm{ml}$ at $5 \mathrm{~h}$; the level then increased to $8.86 \mu \mathrm{g} / \mathrm{ml}$ at $24 \mathrm{~h}$ (Fig. $2(a))$. As a result, no attempt was made to model the absorption phase.

Comparison of the transfer rates for treatments 5 (DL- $\alpha$-tocopheryl acetate) and 6 (D- $\alpha$ tocopheryl acetate) in the first $24 \mathrm{~h}$ was based on a repeated measures analysis of variance. Both the treatment difference and treatment $\times$ time interaction were significant $(P=0.003$ 
and 0.027 ) indicating that transfer rates in the two treatments differed and the difference was not consistent across time. On average, treatment 6 produced much faster transfer rates in the early stages (first $3 \mathrm{~h}$ ) while treatment 5 produced slightly faster transfer over the period from 4 to $24 \mathrm{~h}$. The reversal in relative transfer rates from 4 to $24 \mathrm{~h}$ is at least partially due to the fact that the treatment $6(\mathrm{D}-\alpha$-tocopheryl acetate) profiles peaked between 24 and $31 \mathrm{~h}$ while treatment 5 (DL- $\alpha$-tocopheryl acetate) profiles had an average $t_{\max }$ of $62.5 \mathrm{~h}$. In spite of the longer transfer periods in treatment 5 , the faster transfer of treatment 6 resulted in significantly higher $C_{\max }$ for treatment 6 (Table 2).

Elimination profiles in all three treatments appeared to follow first-order kinetics for a period of time. Following the peak concentrations the decline in concentrations was generally consistent with an exponential model but the profiles tended to arrive at a temporary plateau which was substantially higher than baseline concentrations. Concentrations would remain at this apparent equilibrium level for varying periods of time and then continue to decrease to baseline levels. In many cases the decrease appears to be very abrupt (Fig. 2(b)). Exponential models were fitted to the apparent first-order kinetic portion of the profiles. Treatment 5 and 6 profiles were consistent with a single exponential. Treatment 7 profiles were represented as the sum of three exponentials (Fig. 3, Table 3). Differences in the estimated elimination rate constants for treatments 5 and 6 (Table 2) were not statistically significant.

The first exponential, $A \mathrm{e}^{-\alpha t}$, in the treatment 7 (DL- $\alpha$-tocopherol) profiles represents a rapid distribution phase which was evident within the first 20 min following injection. The second exponential reffects interchange between the central compartment and a shallow peripheral compartment. Beyond $24 \mathrm{~h}$ the profiles were essentially in the terminal elimination phase represented by the slow decline in tocopherol levels in the third exponential term.

In view of the lack of a consistent model representation for the elimination profiles over the entire elimination phase, between treatment comparisons of elimination rates and concentrations were carried out using a repeated measures model and univariate analyses of variance. Sporadic differences in elimination rates were noted at times points where sudden drops in concentration occurred but overall elimination rates over the period $79-319 \mathrm{~h}$ were not significantly different (repeated measure $P=0.39$ for treatment differences). However, the concentrations for treatment 7 were significantly lower over this period because of the rapid elimination that had occurred in the first $72 \mathrm{~h}$.

The tocopherol availability, as measured by the AUC, was significantly larger in treatment $6(P<0.01)$. This difference may be partially due to the elevated initial concentrations in treatment 6 (Table 2 ). When initial concentration was used as a covariate, treatment 6 still had the largest AUC but differences were no longer statistically significant $(P=0 \cdot 20)$.

\section{DISCUSSION}

The results show that the various tocopherol preparations given orally to sheep were not absorbed with equal effectiveness and that their potency depended on their chemical form. Physiological differences are reflected in the peak concentrations which show that free D$\alpha$-tocopherol was more effectively absorbed through the sheep gut than the other forms of vitamin $\mathrm{E}$, results that are similar to those reported for humans (Horwitt et al. 1984). Horwitt et al. (1984) reported that, in humans, the mean concentration of $\alpha$-tocopherol in the serum was higher during the $24 \mathrm{~h}$ following ingestion of a single oral dose of $\mathrm{D}-\alpha-$ tocopherol than after oral administration of the ester forms. They also found that $D-\alpha-$ tocopheryl acetate was 2.62 times more potent than DL- $\alpha$-tocopheryl acetate in increasing the serum concentration of vitamin E. Baker et al. (1980) also reported that, in humans, 
following oral administration of various vitamin $E$ preparations, free $\mathrm{DL}-\alpha$-tocopherol was better absorbed than the esterified (acetylated) DL- $\alpha$-tocopheryl acetate. Recently Baker et al. (1986) reported that their investigations in humans confirmed the currently accepted biopotency for $1 \mathrm{mg}$ each of D- $\alpha$ - and DL- $\alpha$-tocopheryl acetate of $0.91 \mathrm{mg}$ and $0.67 \mathrm{mg}$ of $D-\alpha$-tocopherol, respectively. The differences between peak concentrations in serum tocopherol of sheep reflect physiological differences between the various tocopherol forms ingested. Indeed, considering the ratios for maximum concentration: initial concentration $\left(C_{\max }: C_{0}\right)$ shown in Table 1, it appeared that the biological effectiveness of D- $\alpha$-tocopherol was higher than the other preparations given orally to sheep. In addition, the area postdosing, or persistance curve which may be considered to provide a proper measure of relative availability for physiological functions, was significantly higher $(P<0.01)$ for the D- $\alpha$-tocopherol treatment than for the other ingested vitamin $\mathrm{E}$ compounds. The amounts of vitamin E given to sheep, in this experiment, were high but similar to those given orally to sheep by Hidiroglou \& Williams (1987) and intramuscularly by Hidiroglou \& McDowell (1987). These high doses are comparable to amounts administered parentally to premature infants $(\mathrm{g} / \mathrm{kg}$ body-weight basis; Bucher \& Roberts, 1982; Speer et al. 1984).

In the first experiment no statistical difference $(P>0.05)$ was observed for $C_{\max }$ or area between the ingested ester forms (D- or DL- $\alpha$-tocopheryl acetate) or DL- $\alpha$-tocopherol. However, it was observed that $C_{\max }$ and AUC were higher for D- $\alpha$-tocopherol acetate. It is noted that the size of our samples was very small, and the variation between the various treatments may have masked the expected difference between the $\mathrm{D}-\alpha$-tocopheryl acetate and the L-isomer of tocopherol. The reported large variations in the pharmacokinetic values between individuals could probably be explained by a number of factors, such as differences in abomasal pH and rumen retention time (Hidiroglou \& Jenkins, 1974).

From the results of the single oral dose of the various tocopherol preparations it seemed probable that $\mathrm{D}-\alpha$-tocopherol was used more effectively for physiological purposes than the two esters or DL- $\alpha$-tocopherol. This leads us to believe that the oxidative destruction of free tocopherol in the rumen environment is not important, as was suggested by Astrup et al. (1974).

The analyses of the results obtained following parenteral administration of the different forms of the various vitamin $\mathrm{E}$ compounds indicated that the chemical form of vitamin $\mathrm{E}$ injected intravenously also had a significant effect on its transport. Free DL- $\alpha$-tocopherol was transferred immediately while several hours elapsed before the maximum concentration of $\alpha$-tocopherol appeared in the plasma following intravenous administration of the two esterified tocopherol forms. The delayed transport of the ester forms reflects the fact that under normal physiological conditions vitamin $\mathrm{E}$ esters are hydrolysed before utilization (Kelleher \& Losowsky, 1970). Similar differences in transfer characteristics were reported in rabbits (Fitch \& Diehl, 1965) and dogs (Bauernfeind et al. 1974; Newmark et al. 1975; Fujii, 1980). However, these findings did not agree with those of Weber et al. (1964) in rats which showed that radioactive DL- $\alpha$-tocopheryl acetate was transferred more rapidly than its epimer D- $\alpha$-tocopheryl acetate.

In spite of the immediate transfer of free DL- $\alpha$-tocopherol after intravenous administration, its availability as measured by the AUC was lower than that of the ester forms. This reduced availability is the result of the rapid elimination of DL- $\alpha$-tocopherol that occurred in the first few hours after injection. As reported by Fitch \& Diehl (1965) for rabbits, the concentrations of DL- $\alpha$-tocopherol immediately after injection were higher, but rapidly fell to levels much lower than those of $D$ - $\alpha$-tocopheryl acetate. The availability of the $D$ - $\alpha$-tocopheryl acetate was also superior to that of DL- $\alpha$-tocopherol acetate as indicated by the maximum plasma concentrations and the AUC. It seems that in the guts of the sheep in the present experiment, D- $\alpha$-tocopheryl acetate underwent hydrolysis to a greater extent 
than DL- $\alpha$-tocopheryl acetate, as was reported in rats (Ingold et al. 1987). According to Ogihara et al. (1985), for clinical purposes it would be more helpful to provide intravenous $\alpha$-tocopherol than its ester form. Our intravenous studies revealed that $D$ - $\alpha$-tocopheryl acetate is a much better form of intravenous application of vitamin $E$ than DL- $\alpha$-tocopherol or DL- $\alpha$-tocopheryl acetate.

\section{REFERENCES}

Astrup, H. N., Mills, S. E., Cook, L. J. \& Scott, T. W. (1984). Acta Veterinaria Scandinavia 15, 451-453.

Baker, H. N., Frank, O., DeAngelis, B. \& Feingold, S. (1980). Nutrition Reports International 21, 531-536.

Baker, H., Handelman, G. J., Short, S., Machlin, L. J., Bhagavan, H. N., Dratz, E. \& Frank, O. (1986). American Journal of Clinical Nutrition 43, 382-387.

Bauernfeind, J. C., Newmark, H. \& Brin, M. (1974). American Journal of Clinical Nutrition 27, $234-253$.

Bucher, J. R. \& Roberts, R. R. (1982). Pediatric Pharmacology 2, 1-7.

Fitch, C. D. \& Diehl, J. F. (1965). Proceedings of the Society for Experimental Biology 119, 553-557.

Fujii, T. (1980). Vitamins (Japan) 54, 431-439.

Hidiroglou, M. (1986). International Journal for Vitamin and Nutrition Research 56, 247-252.

Hidiroglou, M. \& Jenkins, K. J. (1974). Annales de Biologie Animale, Biochimie, Biophysique 14, $667-677$.

Hidiroglou, M. \& Karpinski, K. (1987). British Journal of Nutrition 58, 113-125.

Hidiroglou, M. \& Williams, C. J. (1987). American Journal of Veterinary Research 47, 1767-1771.

Hidiroglou, N. \& McDowell, L. R. (1987). International Journal for Vitamin and Nutrition Research 57 , 261-266.

Horwitt, M. K., Elliot, W. H., Kanjananggulpany, P. \& Fitch, C. D. (1984). American Journal of Clinical Nutrition 40, 240-245.

Ingold, K. U., Burton, G. W., Foster, D. O., Hughes, M., Lindsay, D. A. \& Webb, A. (1987). Lipids 22, 163-173.

Kelleher, J. \& Losowsky, M. S. (1970). British Journal of Nutrition 24, 1033-1047.

McMurray, C. H. \& Blanchflower, W. J. (1979). Journal of Chromatography 178, 525-531.

Newmark, H. L., Pool, W., Bauernfeind, J. C. \& Ritter, R. (1975). Journal of Pharmaceutical Sciences 64, 655657 .

Ogihara, T., Nishida, Y., Miki, M. \& Mino, M. (1985). Journal of Nutritional Sciences and Vitaminology 31, $169-177$.

SAS Institute (1982). SAS User's Guide. New York: SAS Institute Inc.

Speer, M. E., Blifeld, D., Rudolph, A. J., Chadda, P., Holbein, B. \& Hittner, H. M. (1984). Pediatrics 74, $1107-1112$.

Weber, F., Gloor, U., Wursh, J. \& Wiss, O. (1964). Biochemical and Biophysical Research Communications 14, 189-192.

Winer, B. J. (1971). Statistical Principles in Experimental Design. New York: McGraw-Hill Inc. 